\title{
Determinants of supply chain operational performance
}

\author{
Erna Maulina $^{\mathrm{a}^{*}}$ and Kameswara Natakusumah ${ }^{\mathrm{a}}$
}

\begin{tabular}{l}
\hline Basiness Administration Department, Uni \\
\hline C H R O N I C L E \\
\hline Article history: \\
Received July 12, 2019 \\
Received in revised format July \\
24,2019 \\
Accepted August 22019 \\
Available online \\
August 32019 \\
\hline Keywords: \\
Supply Chain Operational \\
Performance \\
Indonesia \\
Relational Capability \\
IT Capability \\
Organizational Cultural \\
Capability
\end{tabular}

\section{Introduction}

The concept of Supply chain management (SCM) is the group of activities of supply chain to enhance customer value and to achieve competitive advantage on sustainable basis (Cooper et al., 2006; Huan et al., 2004). It represents all those efforts and measures which considered by organization for development of a smooth supply chain process. Supply chain covers all the activities involved for the development of products, disbursement on a final destination, production process, transportation and to coordinate the process through the best information systems required (Zsidisin \& Ritchie, 2009). Currently, the SCM studies are taking more intention of the organizations. This is because most organizations have to access to international market through an effective SCM system (Thomas \& Griffin, 1996). SCM is based on a set of activities to involve all the stakeholders to maintain the competitive environment (Beske, 2012; Asad \& Siddiqui 2019). In recent scenario competition is among in SCM activities (Deshpande, 2012). Many studies indicate that organizations need to be more

* Corresponding author

E-mail address: erna.maulina@unpad.ac.id (E. Maulina)

(C) 2020 by the authors; licensee Growing Science. doi: $10.5267 /$ j.uscm.2019.8.001

\begin{abstract}
rsitas Padjadjaran Bandung, Indonesia
A B S T R A C T

described and of supply chain management ( $\mathrm{SCM}$ ) on the performance of organization's is regarding supply chain in textile and apparel sector which is crucial for the performance of an aggregated gross rate of $6.01 \%$, during forecasted period, 2015-2025. Excellent SCM is necessary for managing this growth. Supply chain role is very crucial in this industry for flourishing but unfortunately operational performance of supply chain is not performing on apparel firm managers which directly supervise to supply chain division. Currently business environment is very competitive and organizations need to focus on SCOP except organizational performance. In this study, we try to find the solution of this problem after
analyzing through jointly the mediating role of Information Technology (IT) and independence effect of Relational Capability (RC) and Organizational Culture Capability (OCC) on supply chain operational performance in Indonesian apparel and textile industry. Results indicate that this research is helpful to resolve supply chain operational issues in Indonesia.
\end{abstract}


focus on SCM performance because it plays an important role in firm performance (CONSTANGIOARA, 2012). SCM concept has been recognized to be vital importance for textiles and apparel industry (Lam \& Postle, 2006; Suryanto \& Komalasari, 2019). However, based on the Maslow's hierarchy of needs, apparel and textile very important elements of physical needs for human survival. Hence, this means that apparel and textiles are the necessary requirements and provide necessary protection for people. Moreover, the apparel and textile sector has exclusive position as a self-governing industry, starts from raw material supply for the production to deliver the final product to end user, with considering total quality management at each step (Khai et al., 2014; Balagobei 2018). With this evidence, indirectly, the researchers were suggested to look for complete chain while studying textile and apparel context. Thus, this sector needs to be considered for more research, as it has a solid position in the Maslow's hierarchy of desires and limited studies have been accomplished.

Indonesia is one of those countries considered as the largest textile producer and ranking in top eight. Industry of garments and textile is one of the oldest in Indonesia and a big source of employment due to labor intensive (Vickers, 2017; Banerjee \& Ofei, 2018). However, Chinese industries create a big threat and taking a dominant position in this sector. Although in whole global textile market China is taking 33\% share and Indonesia is just only 2.01\% (Anderson \& Strutt, 2015; Bosupeng, 2018). The target of Indonesian government is to increase the value of textile export at USD 73 billion till 2025, and $5 \%$ would contribute the share in globe market through export.

\subsection{Supply Chain Operational Performance (SCOP)}

Supply chain operational performance is well-defined as the result of systematic, strategic, and efficient collaboration of the conventional business functions within and outside organization, consists on processes and activities associated with transforming material inputs into finished goods (Bharati \& Chaudhury, 2006; Linic et al., 2011; Boutayeba, 2017). In the context of this research, three elements exist: relational capability, organizational cultural capability and IT capability which are consolidated in measuring supply chain operational performance in order to provide a complete performance measurement throughout the study.

\subsection{Textiles and apparel Industry of Indonesia}

The growth of Indonesian textile is expected during 2015-2025 at AGR of 6.01\%, in revenue terms. The recent agreement on subsidies in tariff are major factors which increase the export to Middle East, European Union and United States.

Based on the report provided by Department of Statistics Indonesia (2016), Indonesian economy registered growth of 5.6\% which Gross Domestic Product (GDP) in current term posted a value of (USD 2,284.80 million) in 2016 and spearheaded by the service and manufacturing sectors. According to Indonesian Textile Association (API), one of the major contributors in manufacturing industry in Indonesia is apparel and textile. The manufacturing sector rose to $4.8 \%$ in 2011,2016 , an improvement from $4.7 \%$ recorded in 2011 , particularly textile and apparel products, which accounted for $1.7 \%$ to the growth within the manufacturing sector. In the last 40 years, technological development enabled textile and apparel industry to implement new procedures and methods to increase the performance (Williams et al., 2017; CHE \& Sundjo 2018). Fashion is about technology management which utilized technology as an important element to attract customer and gain mutual benefits (Lee, 2015; Edeme, 2018). The adoption and application of the latest technology are required to develop the full potential of textiles and apparel industry. Likewise, supply chain technology (SCT) is important in contributing to the growth of the economy and their linkages to the manufacturing industry. From aforementioned, we can conclude that, in the short term, textile and apparel industry has a limited impact on the economy, but, in long run competitiveness, it has positively contributed towards the development of the country. 


\section{Literature Review}

\subsection{Issues Related to Supply Chain Operational Performance}

In Asia, technology is the real and major concern for the development of an effective SCM system. There is a feeble accessibility of technology application in numerous developing Asian countries. Bringing down the operational cost has been common in Asia. However, this is also the weakness of Asia to develop an efficient logistics and distribution to diminish the cost. (Li, 2010; Fengyang, 2018) Besides, joint effort is a range of opportunity in Asia. Presently, a huge number of the collaborative efforts are informal (Li, 2010; Georgantopoulos et al., 2018). As a more formal form of collaboration creates, particularly at the industry level, extraordinarily efficiency and cost savings can be realized (Gholami et al., 2013).

From this discussion it is easy to understand, the efficient SCM system is only possible if the latest technologies applied in the right firm on right time, it is the major competitive edge on one organization to other (Motwani et al., 2000; Gyebi et al., 2013). However, it is very hard task and needs a great investment of time and financial resources (Li et al., 2017; Nazempour, \& Yang 2019), A lot of multinational firms enrollee their unit of businesses and acquisitions throughout the global to gain a competitive advantages in supply chain system (Akgün et al., 2013; Negrut, 2017). The huge investment at initial level is restricted the vendors to enter in competitive situation. The multinational firm can adopt this complex and cost intensive system because they have resources and enough budget to finance such plans and it would not be feasible for small and medium businesses to adopt due to resource constraint (Lee et al., 2014). As indicated, most of the business entities in Indonesian's apparel and textile industry are based on medium and small enterprises. According to GBP report (2014), almost $78 \%$ of Indonesian textile and garment industry were medium and small entities. The same situation holds for Thailand and Hong Kong textile industry faced in SCM System (Loon et al., 2016; Nzimande \& Padayachee 2017).

The expansion in medium and small entities is a vital growth engine and core strength of economy (Lee, 2015; Okechukwu \& Hyginus 2017). Specifically, Indonesia textile and apparel SMEs offered utilization of resources, employment opportunities, foreign-currency accumulation, and ultimately enhanced national economic development. Ab Talib et al. (2015) stated that the big organizations are more encouraged to avail the benefits of SCM in Indonesia, but SMEs have not access to skills and resources which enable to get the potential benefits of SCM. Textile and apparel market demand is uncertain and unpredictable. The nature of this industry leads to high market mediation costs such as loss sales opportunities (e.g., stock outs) during peak season or outstrips inventories during low season and gradually obsolete inventories were generated. SCM is a key to provide cost reduction to textile and apparel organizations through increases speed and flexibility. However, true agility requires a high degree of visibility throughout the supply chain. The industry practitioners should recognize the power of supply chain technology adoption in facilitating the issue in this industry (Olowa, 2018).

In current era the role of technology is very crucial which enhance the ability of organization in SCM to get an exclusive benefit from this volatile market. Therefore, firms exploit innovative technologies to direct access to cross border economies as an infinite business to gain economical advantage (Chan \& Qi, 2003; Ozturk \& Ozturk 2018). Besides, information technology (IT) capability has been strong moderating effect on the relationship between service innovation and supply chain performance. Furthermore, prominent role of IT personnel for the reengineering project is crucial to avoid the efforts being failure. For instance, IT personnel provides new technology application training for employees at the right time to avoid shortage of trained personnel that can affect supply chain performance.

In modern business climates, firms have survived by endlessly increasing competition and economy globalization. Generally, IT has made dramatic different in productivity and service level. In current 
market, the use of information technology created a very strengthen network of distribution to achieve the level of customers satisfaction which is able to find everything under the same place such as all rotten life products (Jesus \& Rocio, 2011; Ramuhulu \& Chiranga 2018). The good relationship with customer is crucial to achieve their requirements and expectations. Besides, the application of IT in firms are common now and it has proved to cut the level of cost, improved services, enhanced supply chain partnership, allow direct link to suppliers/ customers, reduced production cost, shorter lead time, and minimized inventory level.

In the boundless business environment, businesses are faced an increasing customers pressure in product customization, enhancement of quality, and response demand more than before (Agami et al., 2012; Leng \& Zailani, 2012; Rismayadi \& Maemunah 2018). Previously, organizations only though about the internal improvement in businesses and reduce the wastage and became more efficient, but now a day's they are not only looking internally but also giving more intention externally to become more efficient and gaining competitive strength. Therefore, continues operational improvements internally and externally make organization more efficient. Socio Economic and Environment Research Institute (2007) stated that "the low labor costs were crucial for textile and apparel organization", but the other aspects are also important such as availability of human capital, employee skills and productivity, infrastructure capability, dependability of suppliers, costs and capital, business environment, and proximity to markets.

The smooth and accurate flow of information from upstream and downstream in the textile and apparel supply chain be essential to increase the overall supply chain performance. Besides, sharing of information with trading partners is likewise significant. In twenty-first century, supply chain technology is necessary to support information sharing. Supply chain is not only a one-way road, but also it stresses on upward and downward flows of information and material. As Wu, and Yguyen (2013) recommended that the information should take from different sources to become competitive. Moreover, the best way to achieve an urgent response of market volatility depends on the partnership between supplier and organization to provide a quality material supply on market demand. They pointed out that commercial success or failures in apparel markets are largely determined by the organizational culture capability such as flexible and responsive to rapid change in demand.

Some studies (e.g. Christopher \& Lee, 2004; Rosli \& Siong 2018) revealed that organizational structures were not up to the level which meet the challenges to fulfill the uncertain demand. Instead, a responsive organization and agile supply chain are required to drive the supply chain. This is because currently much competitive marketplace of textile and apparel fashion industry has been characterised as incredible product. Therefore, textile and apparel supply chain must focus on different issues to be competitive. For achieving this target SCM operational performance will play a vital role. This study has consisted of four constructs to build up the research framework which includes supply chain operational performance as dependent variable, IT capability as mediating variable, (which consists on infrastructure of information technology, IT personnel, IT knowledge, and IT re configurability) relational capability as first independent variable, organizational culture capability (which consists of involvement, consistency, adaptability, and innovativeness) as second independent variable. So, for nurturing the SCM operational performance the role of relational capability and organizational culture capability utilizing through IT capability is very crucial. Fig. 1 shows this framework. The current study shows how IT capabilities increase the supply chain operational performance. Majorly, this study contributes to the literature by examining the role of relational capabilities and organizational culture capabilities with mediation effect of IT capabilities on how to enhance the performance supply chain industry, specifically in Indonesian apparel and textile industry. Therefore, while making the strategies, and policies for better supply chain management this study is helpful for practitioners to consider it for achieving the better operational performance in this industry. 


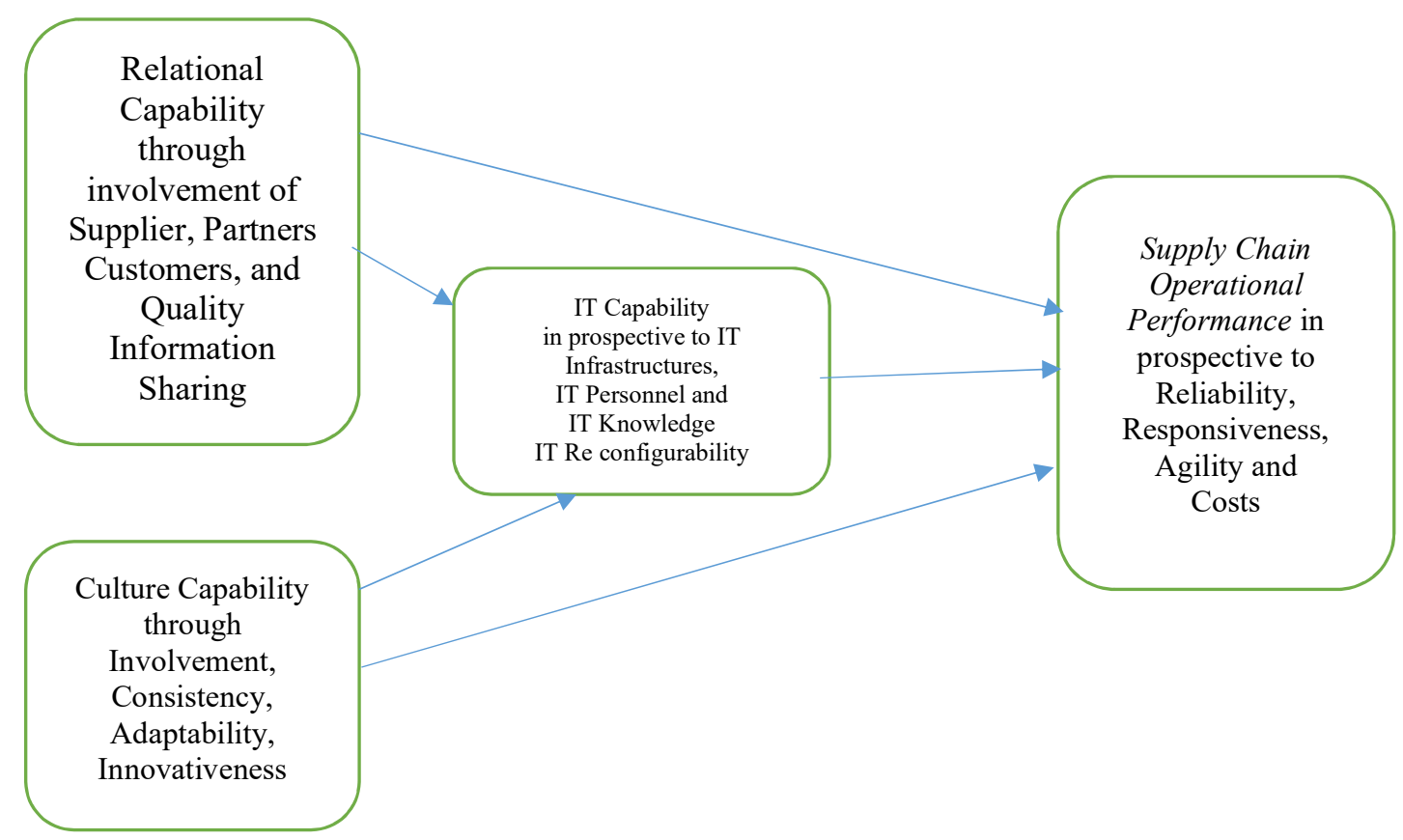

Fig. 1. Theoretical framework

\subsection{Hypothesis Development}

\subsection{Relational Capability $(R C)$}

Relational capability is defined as the ability that two or more people or organizations or things are connected (Power \& Simon, 2004). On the context of this research, relational capability is operationalized as a set of ability that includes partnership with supplier, customer relationship, information sharing, and information quality. Partnership with supplier is explained as the supplier and organization relationship on strategic basis that provides goods or services for the business to achieve significant ongoing benefits. For the Relationship between RC and SCOP in SCM study, few studies found that partnership with supplier information sharing and information quality enhanced the performance of SCOP. The studies suggest that if we make this relationship strong then it can lead to optimize cost of supply chain and also boost up the reliability of supply (Fauziah et al., 2008) and creates flexibility to manage uncertainties in supply and demand. Partnership with supplier is very crucial in apparel and textile industry because if situation changes on market then it can provide quick response. The main benefit of supplier partnership is that the organization enables itself to get timely delivery of raw material for smoothing its operation for final processing. In brief, a good partnership with suppliers enhances performance of overall organization operations and if organization does not create a good partnership relationship then it leads influences badly on the supply chain performance. Studies on information sharing capability can be found on influence on SCOP. Information technology sharing is a well-known manner to increase at least $50 \%$ supply chain performance (Ramayah \& Omar, 2010). Specifically, the high levels of information sharing improved responsiveness and efficiency of all activities in the supply chain. Furthermore, the quality of the information is also absolutely critical to influence the performance of supply chain. Therefore, we conclude that.

$\mathbf{H}_{1}$ : The is a significant relationship between relational capabilities and supply chain operational performance.

$\mathbf{H}_{2}$ : IT capabilities mediate between relational capabilities and supply chain operational performance. 


\subsection{Information Technology Capability (IT)}

Information technology capability is defined as the extent of organization's ability to used systems for storing, retrieving, and sending information (Bharadwaj, 2000). In the context of this research, IT capability is operationalized as the extent of organization's ability that includes IT infrastructures, IT personnel, IT knowledge, and IT re-configurability. The core supply chain technology is excluded in IT infrastructure in this study. IT infrastructures is defined as the hardware or software used directly or indirectly to provide information for users. While, IT personnel is defined as the people employed in an organization's IT department. Besides, IT knowledge is defined as the IT facts, information and descriptions. Moreover, IT re-configurability is defined as the ability to recombine existing IT resources into new configurations to match with the changed environment. The management can utilize the functions of SCM to plan, coordinate, and control logistics knowledge flow, capital flow, and information flow of the business. It enables firms to improved response speed and reduced uncertainty of the supply chain (Govindan et al., 2017). Meanwhile, competition has increasingly become stiff in the global business environments (Chan et al., 2003). Hence, it is crucial that textile and apparel firms to make consensus to enjoy a common goals just like quality enhance, minimize stock holding cost, improved flexibility, timely respond according to market situation (Agami et al., 2012), take those measures which lead to enhance profitability of organization, customer satisfaction (Leng \& Zailani, 2012; Rusomyo et al., 2017), otherwise, the company can lose its market position (Thomas \& Griffin, 1996).

For instance, the Spanish apparel organization, Zara, is the dynamic and hybrid supply chain organization of apparel industry which targets the market of 18-35 years old customers. Most of supply chain partnerships failed due to lack of visibility of demand, so, forecast of demand driven is better than supply driven (Linic et al., 2011). Therefore, Zara is performing excellent in supply chain through quick response and handling visibility problems in apparel industry. To improve SCOP of organization IT capability is recognized a key tool. Specifically, several researches in this field indicate that a good infrastructure of IT leads to a better performance and minimizes the cost and increases operational agility. Besides, IT Capability is also helpful for reducing corruption in operational activities and leads to transparency. Therefore, IT workforces reveal the positive and direct impact on agility services of organizations.

Moreover, IT knowledge is helpful for managing supply chain which is very critical factor in top three success factors. User of IT knowledge needs to be fully aware with this knowledge and utilizes to the performance of business operations. Knowledge of IT can be acquired through courses and training. Further re-configurability of IT impacts positively and significantly on SCM performance. Some contradict finding arises that capability of IT did not have direct effect on supply chain agility, but it creates impact indirectly. Thus, we conclude from this,

H3: There is a significant relationship between IT capabilities and supply Chain operational performance.

\subsection{Organizational Culture Capability (OCC)}

Organizational culture capability is described as the level of behavior or pattern of people's works in an organization to affect the way of people and groups interacts with each other as well as members in the supply chain (Schein et al., 2004). In the context of this research, organizational culture capability is operationalized as the extent of behavior or pattern of people's works in the organization that include involvement, consistency, adaptability, and innovativeness. Involvement is defined as the act of employees takes part or participates in something. While, consistency is described as the capability of employees to have the same behavior, attitude, or quality of work. Besides, adaptability is defined as the ability of employees to cope with unexpected disorders in the environment. In addition, 
innovativeness is defined as the ability of employees to apply new approach or new ways of doing things to meet new requirements, inarticulate needs, or problem solving.

Organizational culture has been proven to be critical factor of organization's performance for many years. Generally, culture has direct effect on organization's success or failure. Several researchers demonstrated that organizational culture must align with organizational goals. This is because organizational culture has a direct and positive significant impact on supply chain performance, specifically improved flexibility and enhanced responsiveness of global SCM. The study of Abdullah et al. (2013) found that organizational culture had a significant effect on supply chain performance of Indonesia SMEs. Furthermore, the study of which includes responses from supply chain professionals that listed in New York's Institute of Supply Management (ISM) indicated that organizational culture has positive direct relationship with supply chain performance.

In 21 st century, textile and apparel organization must be efficient in providing products at low prices while having the ability to rapidly adapt to quick-change market. Besides, the organization must have the ability to consistently provide high quality and innovative products to market at a rapid pace. Technological and administrative innovations are pertaining to supply chain operational management. Several studies found that innovativeness in the supply chain bring benefits to supply chain performance such as improved flexibility, save labor cost and inventory cost. Furthermore, the involvement of employees to participate in related job functions significantly affected the supply chain performance. The study revealed that organizational involvement was important in improving supply chain responsiveness, since it can identify gaps in organizational capabilities. Therefore, it is difficult for organizations to achieve the desired performance without full involvement of employees. This is one of the reasons why Toyota's UK supply chain emphasized on employee involvement and innovativeness in meeting just-in-time supply (Vanichchinchai, 2012).

$\mathbf{H}_{4}$ : There is a significant relationship between organizational culture capabilities and supply chain operational performance.

Hs: IT capabilities mediate the relationship between organizational capabilities and supply chain operational performance relationship.

\section{Research methodology}

The study was employed quantitative method in testing objective theories (e.g., the framework of the study) by investigating the relationship among variables (Levitt et al., 2018). The intent of this study is to examine the relationship of supply chain relational and organizational culture capabilities and also supply chain information technology acceptance towards supply chain operational performance in Indonesian apparel and textile industries. Since this study employed a quantitative research design in conducting the research, the instrument used was survey questionnaires.

\subsection{Population and sampling}

Respondent of the study refers to a set of people or things of interest that the researcher desires to study or make inferences based on a derived sample. This study focused on textiles and apparel companies in Indonesia. Specifically, it was covered seven provinces of Indonesia out of 34 province which are, Bali, Central Kalimantan, Central java, East java, Banten, Jakarta and Bengkulu. We chose only those organizations registered in Indonesian textile association (API) (2018) and country's Investment Coordinating Board (BKPM) (2017) were selected for the population list. A mixed group of participants impacting on supply chain process provides better results in this study, so we have chosen Indonesian apparel and textile supplier's managers, distributers, manufacturer, retailer and service provider. All respondents were involved with the SCM activities and applying supply chain technologies in their organization. 
A sample is a group of participants or individuals selected from a bigger group of population for survey purpose. The appropriate sample size selection is imperative for reducing the sampling error sample size 100 is acceptable, while Guilford (1954) argued that sample size 200 is better, so in this study 200 sample size were chosen for adequacy the results.

\subsection{Data Collection Method}

In this study, postal and online surveys were the main data collection methods. Therefore, first, there must have a cover letter to explain the importance and objective of the research in the context of SCM in Indonesia textile and apparel industry.

Information were collected through mail survey and we prepared a questionnaire which consist on questions relevant to each variable. This questionnaire was distributed via mail survey, which consists five-point Likert scale. This 5-point Likert scale was used to enhance the respondent feedback which ranging from strongly agree to strongly disagree.

The unit of analysis of this study was organization. The targeted survey subjects for managing directors, SCM managers, planning\& development managers, procurement managers, purchasing, and customer service manager whose most responsible for SCM or direct deal with a customer, supplier, and inventory control) to represent their organization to provide information in order to maximize the validity for this research content. Therefore, middle level employees in Indonesian textile and apparel companies were considered appropriate to participate in this study. Moreover, selection of the most fitting statistical instrument depends on many aspects, such as, nature of the research, objective of research and type of data and many others so in this study Smart-PLS 3used for better interpreting results.

\subsection{Measurement model assessment}

Model of measurement is analyzed on the basis of smart PLS 3. Measurement model has been assessed and examined Cronbach alpha, composite reliability, factor loading, discriminant validity and average extracted variance. In Fig. 2 and Table 1 present the results of the measurement model.

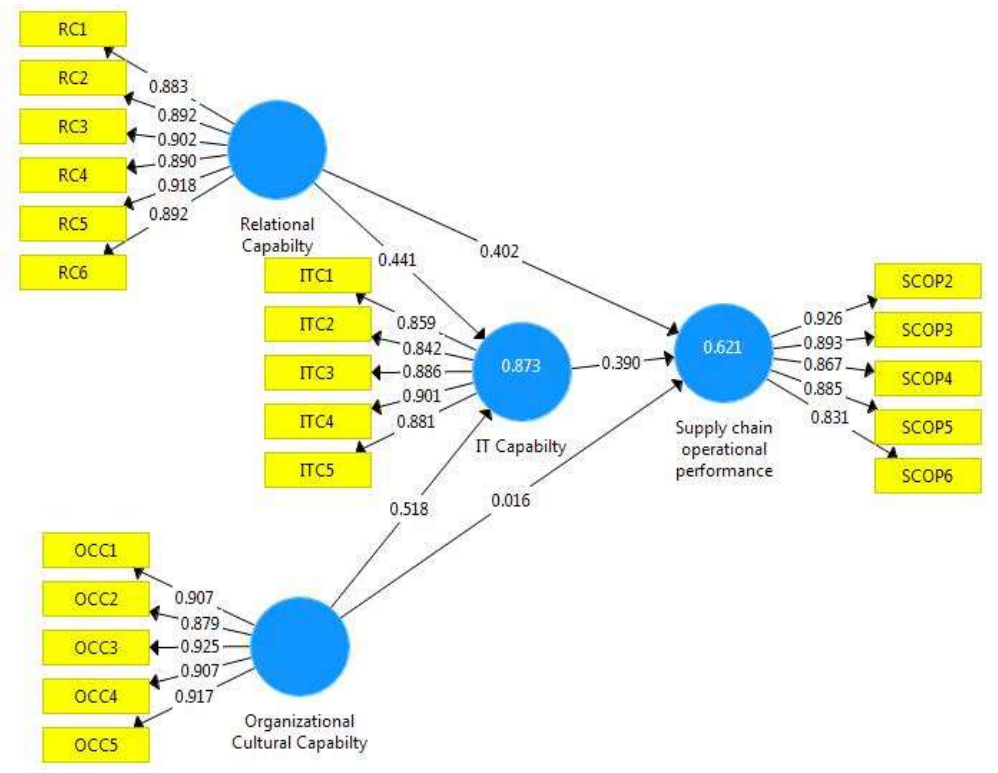

Fig. 2. Measurement Model Assessment.

Measurement model contains the values before hypothesis testing. This model shows the value of factor loading and $\mathrm{R}^{2}$ values of variables. 
Table 1

Internal Consistency, Convergent Validity, composite reliability and AVE

\begin{tabular}{|c|c|c|c|c|c|}
\hline Construct & Indicators & Loadings & Cronbach's alpha & Composite Reliability & AVE \\
\hline \multirow[t]{6}{*}{ Relational Capability } & $\mathrm{RC} 1$ & .883 & .951 & .961 & .803 \\
\hline & $\mathrm{RC} 2$ & .892 & & & \\
\hline & $\mathrm{RC} 3$ & .902 & & & \\
\hline & $\mathrm{RC} 4$ & .890 & & & \\
\hline & $\mathrm{RC} 5$ & .918 & & & \\
\hline & Rc6 & .892 & & & \\
\hline \multicolumn{2}{|c|}{ Organization culture capability Occ1 } & .907 & .946 & .959 & .823 \\
\hline & Occ2 & .879 & & & \\
\hline & Occ3 & .925 & & & \\
\hline & Occ4 & .907 & & & \\
\hline & Occ5 & .917 & & & \\
\hline \multirow[t]{5}{*}{ IT Capability } & ITc1 & .859 & .923 & .942 & .764 \\
\hline & ITc2 & .842 & & & \\
\hline & ITc3 & .886 & & & \\
\hline & ITc4 & .901 & & & \\
\hline & ITc5 & .881 & & & \\
\hline \multicolumn{2}{|c|}{ Supply Chain Operational performance } & .928 & & \multicolumn{2}{|c|}{.776} \\
\hline \multicolumn{2}{|c|}{ SCOP2 } & .926 & & & \\
\hline & SCOP3 & .893 & & & \\
\hline & SCOP4 & .867 & & & \\
\hline & SCOP5 & .885 & & & \\
\hline & SCOP6 & .831 & & & \\
\hline
\end{tabular}

Source: Based on survey data Author's self-estimate

Table 1 shows factor loading values, Cronbach alpha values, composite reliability values and values of average variance extracted. In the results of factor loading only item no 1 of SCOP is below from 0.7 that's why this item is excluded from the results. According to Heorge and Yallery (2007), value is stated suitable that if Cronbach's alpha value is more than $0.7(\alpha>0.9)$. The result shows in this study that the value is above from 0.8 which is consider excellent. Moreover, composite reliability equal to 0.7 or greater than and AVE value equal or more than 0.5 are considered to be excellent. In this study values of AVE and composite reliability is above the required range and all these values are more than the required benchmark. The construct discriminant validity is shown in Table 2 .

\subsection{Structural model assessment}

The analysis of this model was performed by using of Smart PLS 3. To attain the research objectives analysis performed for direct and indirect effect examination in this model.

Table 2

Discriminant Validity

\begin{tabular}{|c|c|c|c|c|}
\hline & $\begin{array}{c}\text { IT } \\
\text { capability }\end{array}$ & $\begin{array}{l}\text { rganizational } \\
\text { Cultural } \\
\text { capability }\end{array}$ & $\begin{array}{l}\text { Relational } \\
\text { capability }\end{array}$ & $\begin{array}{c}\text { Supply chain } \\
\text { operational } \\
\text { performance }\end{array}$ \\
\hline IT Capability & 0.874 & & & \\
\hline Organizational Cultural Capability & 0.854 & 0.807 & & \\
\hline Relational capability & 0.806 & 0.798 & 0.866 & \\
\hline Supply chain operational performance & 0.869 & 0.733 & 0.77 & 0.821 \\
\hline
\end{tabular}

Source: Based on survey data Author's self-estimate 


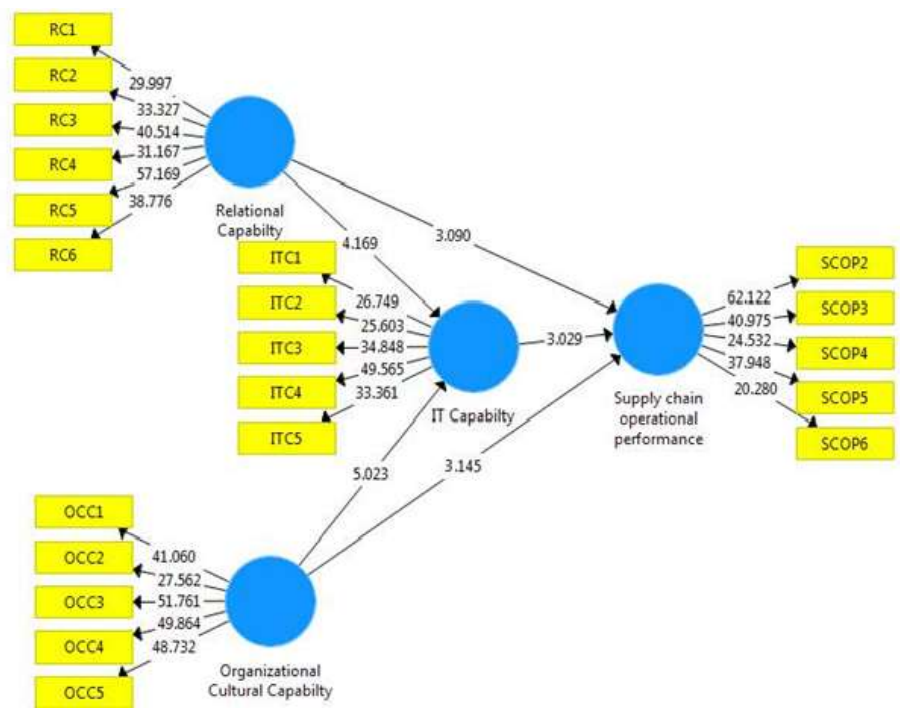

Fig. 3. Structural model assessment (Direct Effect).

Table 3

Direct effect in structural model assessment

\begin{tabular}{|c|c|c|c|c|c|}
\hline & $\begin{array}{l}\text { Original } \\
\text { Sample } \\
(\mathrm{O})\end{array}$ & $\begin{array}{l}\text { Sample } \\
\text { Mean (M) }\end{array}$ & $\begin{array}{l}\text { Standard Deviation } \\
\text { (STDEV) }\end{array}$ & $\begin{array}{l}\text { T Statistics } \\
(|\mathrm{O} / \mathrm{STDEV}| \\
)\end{array}$ & $\mathrm{P}$ Values \\
\hline $\begin{array}{l}\text { IT capability } \rightarrow \text { Supply chain operational } \\
\text { performance }\end{array}$ & 0.39 & 0.378 & 0.129 & 3.029 & 0.003 \\
\hline Organizational Cultural capability $\rightarrow$ IT capability & 0.518 & 0.516 & 0.103 & 5.023 & 0 \\
\hline $\begin{array}{l}\text { Organizational Cultural capability } \rightarrow \text { Supply chain } \\
\text { operational performance }\end{array}$ & 0.016 & 0.022 & 0.11 & 0.145 & 0.885 \\
\hline Relational capability $\rightarrow$ IT capability & 0.441 & 0.444 & 0.106 & 4.169 & 0 \\
\hline $\begin{array}{l}\text { Relational capability } \rightarrow \text { Supply chain operational } \\
\text { performance }\end{array}$ & 0.402 & 0.41 & 0.13 & 3.09 & 0.002 \\
\hline
\end{tabular}

Source: Based on survey data Author's self-estimate

Fig. 3 and Table. 3 show the structural model assessment (Direct Effect). This model shows the results of the direct and indirect effects for testing the hypotheses. Mainly, it shows t values and path coefficient which indicate either agree or disagree with the results of hypotheses. We observe path coefficients were confirmed based on " $\mathrm{t}$ " value. Additionally, $\mathrm{R}-\mathrm{Squared}\left(\mathrm{R}^{2}\right)$ and predictive relevance (Q2) were observed. This research has three (03) direct hypotheses as shown in Fig 3 and Table 4. All direct hypotheses $\left(\mathrm{H}_{1}, \mathrm{H}_{3}\right.$ and $\left.\mathrm{H}_{4}\right)$ were accepted when the level of significance is five percent. Moreover, PLS-SEM bootstrapping was chosen to see the additional effects. Hair et al. (2014) explained that this is the most appropriate tool when we analyze data with small sample. Table 4 shows the results of mediation analysis. It is vibrant that t-value is more than 1.96. Therefore, the indirect effect is significant. Hence, R\&D department mediates the relationship. Hence, $\mathrm{H}_{2}$ and $\mathrm{H}_{5}$ are accepted.

Table 4

Indirect effect in structural model assessment

\begin{tabular}{lccccc}
\hline & $\begin{array}{c}\text { Original } \\
\text { Sample } \\
(\mathrm{O})\end{array}$ & $\begin{array}{c}\text { Sample } \\
\text { Mean } \\
(\mathrm{M})\end{array}$ & $\begin{array}{c}\text { Standard } \\
\text { Deviation } \\
(\text { STDEV })\end{array}$ & $\begin{array}{c}\text { T Statistics } \\
(|\mathrm{O} / \mathrm{STDEV}|)\end{array}$ & P Values \\
\hline $\begin{array}{l}\text { Organizational Cultural Capability } \rightarrow \text { IT } \\
\begin{array}{l}\text { Capability } \rightarrow \text { Supply chain operational } \\
\text { performance }\end{array}\end{array}$ & 0.202 & 0.193 & 0.071 & 2.848 & 0.005 \\
$\begin{array}{l}\text { Relational Capability } \rightarrow \text { IT Capability } \rightarrow \text { Supply } \\
\text { chain operational performance }\end{array}$ & 0.172 & 0.169 & 0.076 & 2.252 & 0.025 \\
\hline
\end{tabular}

Source: Based on survey data Author's self-estimate 
Moreover, by following the suggestions of Hair et al. (2014), while examining the mediation effect, the procedure of Preacher and Hayes (2008) was followed and the indirect effect was examined. Therefore, the current study analyzed the effect of IT capability as a mediator through Smart PLS3.0 (Henseler et al., 2015) by bootstrapping technique and it did the re-sampling of 500 to examine t-value.

\section{Discussion and Conclusion}

Now a day's business situation, the existence of rivalry organization is no more between businesses, but between competitive edges on SCM. Research indicates that the growth of organization businesses is observed according to the performance of supply chain. The role of information technology in improving supply chain network is the major factor which indirectly boosts the performance of organization. Therefore, to facilitate the better supply chain management, IT adoption is unavoidable. To provide a competitive model for current business environment, this study has observed the relationship of some major supply chain capabilities, namely relational capability, information technology capability, and organizational culture capability to boost up the SCOP of organization. This study further investigated whether or not supply chain information technology implementation mediated the relationship between supply chain relational capabilities and SCOP. The current study examined the role of relational capability to boost the performance of operational supply chain management organizational cultural capability in textile and apparel industry in Indonesia. Data were collected from the managerial employees of apparel and textile companies in Indonesia. Findings of the study revealed that, supplier partnership, information quality and customer relationship, information sharing make relational capability of apparel and textile industry and the relationship of this capability on SCOP was positive and significant. Textile and apparel industries collaboration with supplier's partnership and customer's relationship made a strong supply chain channel which had a positive significant impact on overall operational performance of supply chain. Collaboration with customers, suppliers and external partners promoted the relationship between industry and new market which ultimately generated the new businesses for textile industries.

Quantitative findings with triangulation of research findings offer considerable practical implications for the model in this study. The empirical findings further revealed that information technology adoption appreciated the contribution of supply chain capabilities. In addition to the empirical findings, the indirect effect of information technology adoption successfully contributed to the relationships of $\mathrm{SCC}$ and SCOP.

Consequently, current study has contributed to the literature of SCM through its adoption of resource-based view theory, diffusion of innovation theory, and technology organizationenvironment theory simultaneously. This in turn suggests useful improvement strategies for Indonesia textile and apparel organization. However, some limitations like access to data and only limited to some specific provinces of Indonesia of this study were identified and recommendations for future study were discussed to extent the knowledge of the model under study in the near future.

\section{References}

Ab Talib, M. S., Abdul Hamid, A. B., \& Thoo, A. C. (2015). Critical success factors of supply chain management: a literature survey and Pareto analysis. EuroMed Journal of Business, 10(2), 234-263.

Agami, N., Saleh, M., \& Rasmy, M. (2012). A hybrid dynamic framework for supply chain performance improvement. IEEE Systems Journal, 6(3), 469-478.

Akgün, A. E., Koçoğlu, İ., \& İmamoğlu, S. Z. (2013). An emerging consumer experience: Emotional branding. Procedia-Social and Behavioral Sciences, 99, 503-508.

Anderson, K., \& Strutt, A. (2015). Implications for Indonesia of Asia's rise in the global economy. Bulletin of Indonesian Economic Studies, 51(1), 69-94.

Asad, M., \& Siddiqui, D. A. (2019). Determinants of mutual funds performance in Pakistan. International Journal of Social and Administrative Sciences, 4(2), 85-107. 
Balagobei, S. (2018). Corporate governance and firm performance: Empirical evidence from emerging market. Asian Economic and Financial Review, 8(12), 1415-1421.

Banerjee, R., \& Ofei, P. (2018). Ownership structure and bank performance: Empirical evidence from the UAE. Asian Economic and Financial Review, 8(12), 1422-1438.

Bosupeng, M. (2018). Leading indicators and financial crisis: A multi-sectoral approach using signal extraction. Journal of Empirical Studies, 5(1), 20-44.

Boutayeba, F. (2017). Estimating the returns to education in Algeria. Asian Journal of Economic Modelling, 5(2), 147-153.

Beske, P. (2012). Dynamic capabilities and sustainable supply chain management. International Journal of Physical Distribution \& Logistics Management, 42(4), 372-387.

Bharadwaj, A. S. (2000). A resource-based perspective on information technology capability and firm performance: an empirical investigation. MIS quarterly, 24(1), 169-196.

Bharati, P., \& Chaudhury, A. (2006). Studying the current status: Examining the extent and nature of adoption of technologies by micro, small and medium sized manufacturing firms in the greater Boston area. Communications of the ACM, 49(10), 88-93.

CHE, G. N., \& Sundjo, F. (2018). Determinants of female labour force participation in Cameroon. International Journal of Applied Economics, Finance and Accounting, 3(2), 88-103.

Chan, F. T., Qi, H., Chan, H. K., Lau, H. C., \& Ip, R. W. (2003). A conceptual model of performance measurement for supply chains. Management decision, 41(7), 635-642.

Christopher, M., \& Lee, H. (2004). Mitigating supply chain risk through improved confidence. International Journal of Physical Distribution \& Logistics Management, 34(5), 388-396.

CONSTANGIOARA, A. (2012). The Impact of Supply Chain Performance on Organizational Performance. Journal of Electrical \& Electronics Engineering, 5(2).

Cooper, D. R., Schindler, P. S., \& Sun, J. (2006). Business research methods (Vol. 9): McGraw-Hill Irwin New York.

Edeme, R. K. (2018). Revisiting the economic growth-welfare linkages: Empirical evidence from Nigeria. Asian Themes in Social Sciences Research, 1(1), 28-33.

Fengyang, W. U. (2018). An analysis of Chinas poverty research based on CiteSpace. Journal of Social Economics Research, 5(2), 75-84.

Fauziah, Taib, M., Ramayah, T., \& Abdul Razak, D. (2008). Factors influencing intention to use diminishing partnership home financing. International Journal of Islamic and Middle Eastern Finance and Management, 1(3), 235-248.

Gholami, R., Sulaiman, A. B., Ramayah, T., \& Molla, A. (2013). Senior managers' perception on green information systems (IS) adoption and environmental performance: Results from a field survey. Information \& Management, 50(7), 431-438.

Govindan, K., Fattahi, M., \& Keyvanshokooh, E. (2017). Supply chain network design under uncertainty: A comprehensive review and future research directions. European Journal of Operational Research, 263(1), 108-141.

Georgantopoulos, A. G., Poutos, E. I., \& Eriotis, N. (2018). Recent developments and trends in accounting information systems. Journal of Accounting, Business and Finance Research, 3(1), 1-9.

Gyebi, F., Owusu, M., \& Etroo, J. K. (2013). Foreign direct investment and gross domestic Product in Ghana. International Journal of Academic Research in Accounting, Finance and Management Services, 3(3), 256-65

Henseler, J., Ringle, C. M., \& Sarstedt, M. (2015). A new criterion for assessing discriminant validity in variance-based structural equation modeling. Journal of the Academy of Marketing Science, 43(1), 115-135.

Huan, S. H., Sheoran, S. K., \& Wang, G. (2004). A review and analysis of supply chain operations reference (SCOR) model. Supply Chain Management: An International Journal, 9(1), 23-29.

Khai, L. L., Mohamed Udin, Z., \& Hassan, M. G. (2014). A review of relational capabilities on supply chain performance in textile and apparel industry.

Lam, J. K., \& Postle, R. (2006). Textile and apparel supply chain management in Hong Kong. International Journal of Clothing Science and Technology, 18(4), 265-277. 
Lee, K.-L., Mohamed Udin, Z., \& Hassan, M. G. (2014). Global supply chain capabilities in Malaysian textile and apparel industry. International Journal of Supply Chain Management (IJSCM), 3(2), 3140.

Lee, K. L. (2015). Relationship of supply chain capabilities and supply chain technology adoption towards supply chain operational performance in textile and apparel industry. Universiti Utara Malaysia.

Leng, F. L., \& Zailani, S. (2012). Effects of information, material and financial flows on supply chain performance: A study of manufacturing companies in Malaysia. International Journal of Management, 29(1), 293.

Levitt, H. M., Bamberg, M., Creswell, J. W., Frost, D. M., Josselson, R., \& Suárez-Orozco, C. (2018). Journal article reporting standards for qualitative primary, qualitative meta-analytic, and mixed methods research in psychology: The APA Publications and Communications Board task force report. American Psychologist, 73(1), 26.

Li, S. (2010). Does mandatory adoption of International Financial Reporting Standards in the European Union reduce the cost of equity capital? The accounting review, 85(2), 607-636.

Li, X., Wu, Q., Holsapple, C. W., \& Goldsby, T. (2017). An empirical examination of firm financial performance along dimensions of supply chain resilience. Management Research Review, 40(3), 254-269.

Linic, S., Christopher, P., \& Ingram, D. B. (2011). Plasmonic-metal nanostructures for efficient conversion of solar to chemical energy. Nature Materials, 10(12), 911.

Loon, L. K., Hassan, M. G., \& Udin, Z. M. (2016). The effect of supply chain technology adoption: An empirical study of textile and apparel industry in Malaysia. Journal of Engineering and Applied Sciences, 100(8), 1727-1734.

Motwani, J., Madan, M., \& Gunasekaran, A. (2000). Information technology in managing global supply chains. Logistics Information Management, 13(5), 320-327.

Nazempour, R., \& Yang, J. (2019). A study to assess the personality of supply chain managers and its effect on supply chain performance. International Journal of Social and Administrative Sciences, 4(1), 57-65.

Negrut, V. (2017). Overview of the most common types of maladministration raised at EU level. International Journal of Public Policy and Administration Research, 4(2), 35-40.

Nzimande, N., \& Padayachee, P. (2017). Evaluation of the current procurement planning process in a district municipality. International Journal of Public Policy and Administration Research, 4(1), 1934.

Okechukwu, O. C., \& Hyginus, O. O. (2017). National security and democratization in Nigeria: The Case of Insurgence. International Journal of Public Policy and Administration Research, 4(1), 1218.

Olowa, O. W. (2018). Determinants of rural residential solid waste collection services in Lagos State. International Journal of Sustainable Development \& World Policy, 7(1), 1-7.

Ozturk, F., \& Ozturk, S. (2018). Exploring the nexus of coal consumption, economic growth, energy prices and technological innovation in Turkey. Asian Economic and Financial Review, 8(12), 14061414.

Power, D., \& Simon, A. (2004). Adoption and diffusion in technology implementation: a supply chain study. International Journal of Operations \& Production Management, 24(6), 566-587.

Preacher, K. J., \& Hayes, A. F. (2008). Assessing mediation in communication research. The Sage sourcebook of advanced data analysis methods for communication research, 13-54.

Ramayah, T., \& Omar, R. (2010). Information exchange and supply chain performance. International Journal of Information Technology \& Decision Making, 9(01), 35-52.

Ramuhulu, M., \& Chiranga, N. (2018). An investigation into the causes of failures in railway infrastructure at Transnet Freight Rail-A case of the steel and cement business unit. International Journal of Sustainable Development \& World Policy, 7(1), 8-26. 
Rismayadi, B., \& Maemunah, M. (2018). Creative economy to increase community revenue Based on tourism object, Medalsari Village, Pangkalan District Karawang Regency. Journal of Accounting, Business and Finance Research, 3(1), 28-35.

Rosli, A., \& Siong, T. I. (2018). Determinants of customers satisfaction towards services provided by agencies in Urban Transformation Centre (UTC). International Journal of Economics, Business and Management Studies, 5(1), 9-15.

Rusomyo, R., Junlin, H., \& Mangare, C. (2017). The role of social networks as survival strategies in Agro-Pastoral communities in arid and semi-arid lands in Tanzania. Asian Development Policy Review, 5(2), 90-99.

Schein, S. M., O'brien, S. A., Leftwich, J. J., \& Broughton, S. (2004). Systems and methods for contextually linking television program information: Google Patents.

Suryanto, T., \& Komalasari, A. (2019). Effect of mandatory adoption of international financial reporting standard (IFRS) on supply chain management: A case of Indonesian dairy industry. Uncertain Supply Chain Management, 7(2), 169-178.

Thomas, D. J., \& Griffin, P. M. (1996). Coordinated supply chain management. European journal of Operational Research, 94(1), 1-15.

Vanichchinchai, A. (2012). The relationship between employee involvement, partnership management and supply performance: Findings from a developing country. International Journal of Productivity and Performance Management, 61(2), 157-172.

Vickers, A. (2017). Clothing Production in Indonesia: A Divided Industry. Institutions and Economies, 41-60.

Williams, C., Colovic, A., \& Zhu, J. (2017). Integration-responsiveness, local hires and subsidiary performance amidst turbulence: Insights from a survey of Chinese subsidiaries. Journal of World Business, 52(6), 842-853.

Zsidisin, G. A., \& Ritchie, B. (2009). Supply chain risk management-developments, issues and challenges Supply Chain Risk (pp. 1-12): Springer.

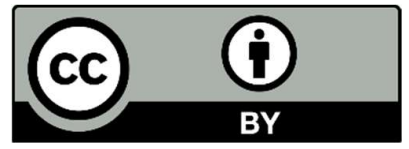

(C) 2020 by the authors; licensee Growing Science, Canada. This is an open access article distributed under the terms and conditions of the Creative Commons Attribution (CC-BY) license (http://creativecommons.org/licenses/by/4.0/). 